\title{
PHYSICAL SENSORS
}

\section{СЕНСОРИ ФІЗИЧНИХ ВЕЛИЧИН}

УДК 617.7-537.32-073

\section{ТЕРМОЭЛЕКТРИЧЕСКИЕ ДАТЧИКИ ДЛЯ РЕГИСТРАЦИИ ВНУТРИГЛАЗНОЙ ТЕМПЕРАТУРЫ}

\author{
Л. И. Анатычук ${ }^{1,2}$, Н. В. Пасечникова ${ }^{3}$ Р. Р. Кобылянский ${ }^{1,2}$, Н. В. Гаврилюк ${ }^{1}$, В. А. Науменко ${ }^{3}$, \\ В. В. Мирненко , Р. Э. Назаретян ${ }^{3}$ О. С. Задорожный \\ ${ }^{1}$ Институт термоэлектричества НАН и МОН Украины, ул. Науки, 1, г. Черновцы, 58029, \\ Украина; anatych@gmail.com, romakobylianskyi@ukr.net; \\ 2 Черновицкий национальный университет им. Ю. Федьковича, ул. Коцюбинского, 2 , \\ г. Черновцы, 58012, Украина; \\ ${ }^{3}$ ГУ «Институт глазных болезней и тканевой терапии им. В.П. Филатова НАМН Украины», \\ Французский бульвар, 49/51, г. Одесса, 65061, Украина, \\ тел. +38-067-4862026, filatovinfo@ukr.net, zadoroleg@mail.ru
}

\section{ТЕРМОЭЛЕКТРИЧЕСКИЕ ДАТЧИКИ ДЛЯ РЕГИСТРАЦИИ ВНУТРИГЛАЗНОЙ ТЕМПЕРАТУРЫ}

\section{Л. И. Анатычук, Н. В. Пасечникова, Р. Р. Кобылянский, Н. В. Гаврилюк В. А. Науменко, В. В. Мирненко, Р. Э. Назаретян, О. С. Задорожный}

\begin{abstract}
Аннотация. В работе представлены результаты разработки и экспериментальных исследований многоканального термоэлектрического устройства с измерительными термопарными датчиками, предназначенными для измерения внутриглазной температуры. Описаны принцип работы, строение и технические характеристики такого устройства, а также его преимущества перед известными мировыми аналогами. С помощью разработанного устройства в эксперименте in vivo определены особенности распределения температуры в глазу кролика при различной температуре окружающей среды.
\end{abstract}

Ключевые слова: термоэлектрический датчик, внутриглазная температура, глаз кролика 


\title{
ТЕРМОЕЛЕКТРИЧНІ ДАТЧИКИ ДЛЯ РЕССТРАЦЇ̈ ВНУТРІШНЬООЧНОЇ ТЕМПЕРАТУРИ
}

\author{
Л. І. Анатичук, Н. В. Пасєчнікова, Р. Р. Кобилянський, М. В. Гаврилюк, В. О. Науменко, \\ В. В. Мирненко, Р. Е. Назаретян, О. С. Задорожний
}

\begin{abstract}
Анотація. У роботі представлені результати розробки та експериментальних досліджень багатоканального термоелектричного пристрою з вимірювальними термопарними датчиками, призначеними для вимірювання внутрішньоочної температури. Описано принцип роботи, будову і технічні характеристики такого пристрою, а також його переваги перед відомими світовими аналогами. За допомогою розробленого пристрою в експерименті in vivo визначено особливості розподілу температури в оці кролика при різній температурі навколишнього середовища.
\end{abstract}

Ключові слова: термоелектричний датчик, внутрішньоочна температура, око кролика

\section{THERMOELECTRIC SENSORS FOR REGISTRATION OF INTRAOCULAR TEMPERATURE}

\author{
L. I. Anatychuk, N. V. Pasyechnikova, R. R. Kobylianskyi, N. V. Gavrilyuk, V. A. Naumenko, \\ V. V. Myrnenko, R. E. Nazaretyan, O. S. Zadorozhnyy
}

\begin{abstract}
The paper presents the results of development and experimental study of multichannel thermoelectric device with thermocouple sensors for intraocular temperature measurement. The working principle, structure and technical characteristics of this device and its advantages over the known world analogues were described. Intraocular temperature distribution in the rabbit eye at different ambient temperature was experimentally studied.
\end{abstract}

Keywords: thermoelectric sensor, intraocular temperature, rabbit eye

Вступление. Искусственная гипотермия широко применяется в ходе кардиохирургических вмешательств и считается эффективным способом нейропротекции. Выполнение таких операций требует непрерывного мониторинга температуры тела больного [1]. Для хирургического лечения ряда глазных заболеваний (например, отслойка сетчатки) используются ирригационные растворы с температурой ниже температуры внутриглазных сред. Следовательно, эти хирургические вмешательства также выполняются в условиях искусственной локальной гипотермии глаза и требуют мониторинга внутриглазной температуры в ходе операции для обеспечения максимальной ретинопротекции. Однако сегодня этому вопросу не уделяется должного внимания. На наш взгляд температурный контроль во время проведения офтальмохирургических вмешательств повысит как эффективность, так и безопасность проводимого лечения.

Для измерения температуры глаза было предложено использовать бесконтактные и контактные методы. Бесконтактные методы измерения (например, инфракрасная термография) позволяет оценить лишь температуру наружной поверхности глаза [2]. Для измерения внутриглазной температуры был разработан ряд устройств и измерительных зондов $[3,4]$. Однако предложенные устройства и методики измерений имели значительные недостатки, поскольку измерительные зонды изготавливались из материалов с высокой теплопроводностью, что приводило к ошибкам измерений температуры [5]. Следовательно, разработка новых измерительных устройств с учетом уже 
известных недостатков позволит повысить точность регистрируемых внутриглазных температур.

Цель. Разработать термоэлектрические датчики для измерения внутриглазной температуры и изучить в эксперименте особенности распределения температуры в различных отделах глаза кролика в зависимости от температуры окружающей среды.

Материал и методы. Термоэлектрическое устройство для измерения внутриглазной температуры было разработано в Институте термоэлектричества НАН и МОН Украины в рамках договора о сотрудничестве с ГУ «Институт глазных болезней и тканевой терапии им. В.П. Филатова НАМН Украины» [6-8]. Устройство предназначено для измерения температуры тканей биологических объектов и исследования динамических тепловых процессов, происходящих в органах биологических объектов. Устройство состоит из микропроцессорного модуля регистрации температуры, измерительных зондов с термоэлектрическими датчиками, стыковочного устройства, а также компьютера с программным обеспечением для визуализации и регистрации температурных показателей в режиме реального времени. С помощью USBкабеля результаты измерений температуры могут быть переданы на персональный компьютер. Внешний вид термоэлектрического устройства и измерительного термопарного зонда приведены на рисунке 1.

Термоэлектрические датчики температуры изготовлены на основе термопар L-типа (хромель-копель). Датчик размещен в корпусе стандартной канюли из политетрафторэтилена. Спай термопары приварен к теплоконцентратору из медицинской нержавеющей стали и закреплен на конце иглы канюли. Подводящие провода термопары переходят из канюли в кабель длиной 1.5 м и заканчиваются вилкой. Стык кабеля и канюли герметизирован медицинским силиконовым герметиком, который является химически нейтральным и допускает термическую или химическую стерилизацию изделия (как обычного медицинского инструмента).

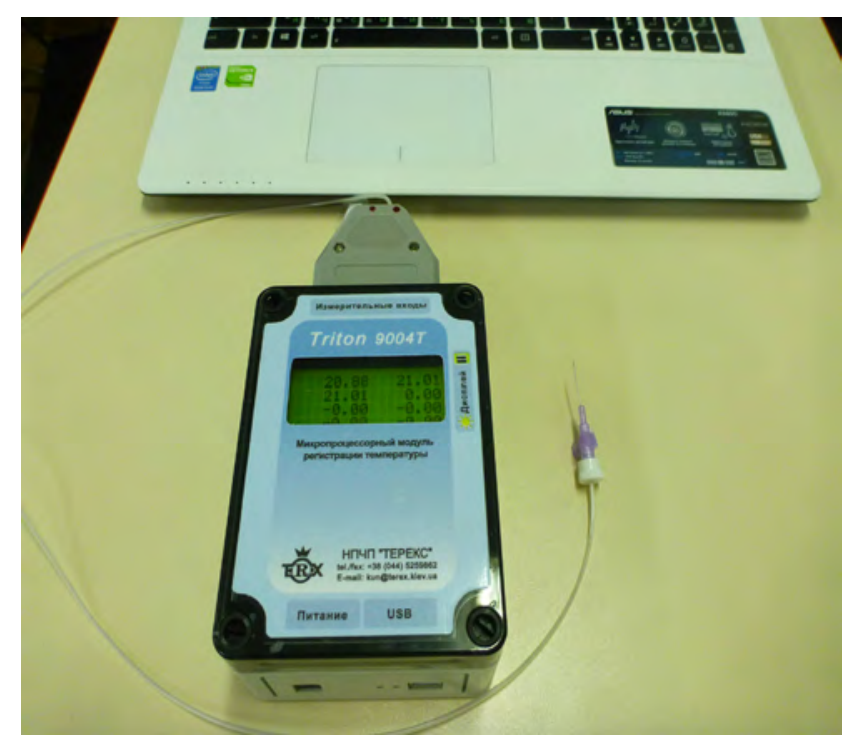

Рис.1а. Внешний вид термоэлектрического устройства для регистрации внутриглазной температуры

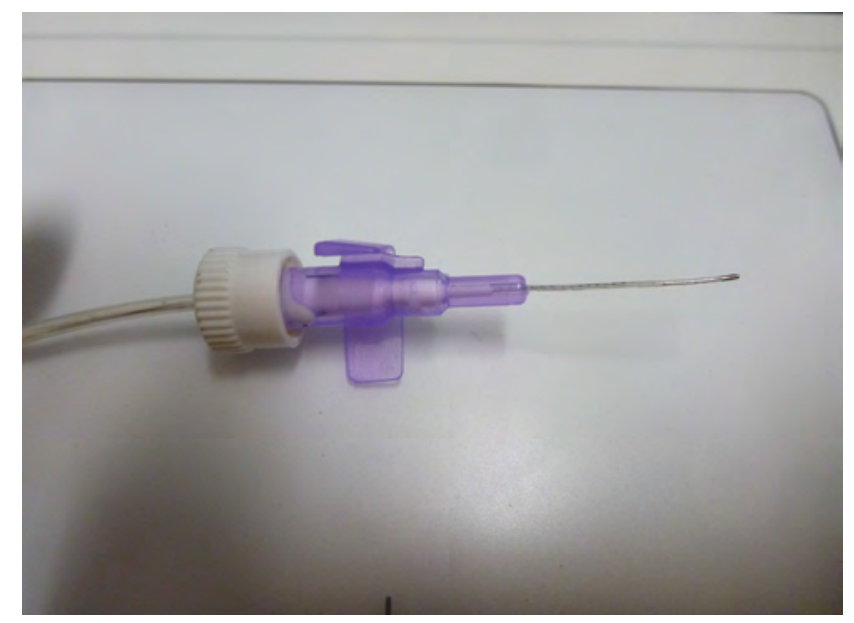

Рис.1б. Внешний вид измерительного зонда с термоэлектрическим датчиком температуры

С помощью вилки через стыковочное устройство измерительный зонд подключается к микропроцессорному модулю регистрации температуры. Стыковочный модуль имеет 4 розетки, к которым может быть одновременно подключено до 4 термоэлектрических датчиков. Подключается стыковочное устройство модуля регистрации температур с помощью разъема DB-37f. Розетки в стыковочном устройстве смонтированы на медном теплоконцентраторе, в котором тоже размещен прецизионный датчик температуры (платиновый термометр сопротивления). С его помощью 
измеряется температура «холодных» концов термопар - опорная температура.

Вилки измерительных зондов и розетки стыковочного устройства имеют обозначения полярности. Для уменьшения уровня наводок неиспользованные входы измерителя закорочены заглушками - отдельные вилки с закороченными штырьками.

Микропроцессорный модуль регистрации температур выполнен на основе прибоpa Triton-9004T, который имеет 8-канальный 24-разрядный аналогово-цифровой преобразователь (АЦП). В таком измерителе температуры используются первых 4 канала, а остальные каналы закорочены. При необходимости их можно «разкоротить» и использовать для дополнительного измерения еще по 4 каналам. Максимальное входное напряжение измерительного канала \pm 1.17 В. Модуль регистрации температуры питается от аккумуляторной батареи, а также может работать от сетевого адаптера или получать питание через USBкабель при совместной работе с компьютером. С помощью такого адаптера выполняется зарядка аккумуляторной батареи. Подзарядка аккумулятора устройства также происходит от персонального компьютера.
Особенностью микропроцессорного модуля регистрации температуры является возможность отдельно устанавливать чувствительность для каждого из каналов в зависимости от типа термопар. Устройство может измерять температуру с заданным временным интервалом в диапазоне от 4 секунд до 2 часов. Данные о результатах измерений записываются в энергонезависимую память. Емкость памяти устройства - 50 тысяч ячеек. Программирование каналов микропроцессорного модуля регистрации и считывание информации выполняется с помощью персонального компьютера через USB-кабель.

Технические характеристики термоэлектрического устройства для измерения внутриглазной температуры представлены в таблице 1.

В эксперименте in vivo на 21 кролике (42 глаза) породы Шиншилла (возраст 1 год, масca 3.5-4 кг) после эпибульбарной анестезии проводилось измерение температуры наружной поверхности роговицы путем прямого контакта с наконечником зонда. Регистрация температуры проводилась в режиме реального времени через каждые 4 секунды, и выполнялось не менее пяти измерений в каждом отделе. Далее температура регистрировалась

Таблица 1

Технические характеристики термоэлектрического устройства для измерения внутриглазной температуры [7]

\begin{tabular}{|c|c|c|}
\hline № & Технические характеристики & Значение \\
\hline 1. & Диапазон измерения температуры & $(-10 \div+120)^{\circ} \mathrm{C}$ \\
\hline 2. & Точность измерения температуры & $\pm 0,05^{\circ} \mathrm{C}$ \\
\hline 3. & Количество каналов измерения температуры & 4 \\
\hline 4. & Период регистрации температуры & от 4 с до 2 час. \\
\hline 5. & Диаметр измерительных зондов & 0,6 мм \\
\hline 6. & Измерение температуры в режиме реального времени & + \\
\hline 7. & $\begin{array}{l}\text { Время непрерывной работы устройства } \\
\text { заряженных аккумуляторов }\end{array}$ & 100 час. \\
\hline 8. & $\begin{array}{l}\text { Питание устройства: } \\
\text { Li-Ion аккумулятор } 950 \text { мA/час } \\
\text { сетевой адаптер AC220V/DC12V,1A }\end{array}$ & $\begin{array}{l}+ \\
+\end{array}$ \\
\hline 9. & Зарядка аккумуляторов от интерфейса USB & + \\
\hline 10. & Тип интерфейса обмена данными с ПК & USB \\
\hline 11. & Геометрические размеры микропроцессорного модуля & $(125 \times 90 \times 60) \mathrm{MM}$ \\
\hline 12. & Геометрические размеры стыковочного устройства & $(70 \times 55 \times 25) \mathrm{мм}$ \\
\hline 13. & Вес устройства & 0,5 кг \\
\hline
\end{tabular}


при помещении измерительного зонда в нижний свод конъюнктивы, а затем в верхний свод конъюнктивы. После введения кролика в наркоз температура измерялась повторно на наружной поверхности роговицы и в сводах конъюнктивы, а далее, после формирования хирургического доступа, температура измерялась в передней камере глаза, в переднем, среднем и заднем отделах стекловидного тела, в сетчатке/сосудистой оболочке заднего полюса глаза, в субтеноновом пространстве. В переднюю камеру измерительный зонд вводился через туннельный парацентез размером 0.7 мм, в стекловидное тело - через склеротомию диаметром 0.6 мм в проекции плоской части цилиарного тела в 2-3 мм от лимба. В субтеноново пространство термозонд вводился через конъюнктивальный разрез в верхневнутреннем квадранте.

Также проводилась регистрация ректальной температуры кролика, температуры и относительной влажности воздуха в помещении. Bcex экспериментальных животных разделили на 3 группы. В первой группе (11 кроликов, 22 глаза) проводилось измерение температуры в различных отделах глаза при температуре окружающей среды $23-25^{\circ} \mathrm{C}$, во второй группе (5 кроликов, 10 глаз) - $14.5-15.5^{\circ} \mathrm{C}$, в третьей группе (5 кроликов, 10 глаз) $-30-32^{\circ} \mathrm{C}$.

Всем экспериментальным животным проводилась биомикроскопия и офтальмоскопия. При проведении хирургических вмешательств применялся наркоз в виде внутримышечных инъекций $10 \%$ раствора тиопентала натрия в дозе 1.0 мл на 1 кг массы животного. На подготовительном этапе к хирургическому вмешательству и в ходе операции в оба глаза выполнялись инстилляции $0.5 \%$ раствора проксиметакаина гидрохлорида с периодичностью 20 минут. Следуя правилам асептики и антисептики, после хирургического вмешательства кроликам проводились инстилляции $20 \%$ раствора сульфацил-натрия, $0.3 \%$ раствора офлоксацина.

Работа с экспериментальными животными проводилась согласно Европейской конвенции о защите позвоночных животных, используемых для исследовательских и других научных целей (Страсбург, 1986), и закону Украины «О защите животных от жестокого обращения» (2006). Для статистической обработки данных исследования была использована программа Statistica 10.0.

Результаты. При анализе полученных результатов значимых различий в температурных показателях правого и левого глаза экспериментальных животных во всех трех группах выявлено не было. Это наблюдение относится как к наружным отделам глаза, в которых проводились измерения (нижний конъюнктивальный свод, верхний конъюнктивальный свод, наружная поверхность роговицы), так и внутренним отделам глаза кролика (передняя камера, различные отделы стекловидного тела,

Таблица 2

\section{Распределение температуры в различных отделах глаза кролика}

\begin{tabular}{|l|c|c|c|}
\hline Отдел глазного яблока & $\begin{array}{c}\text { Средняя t в 1 } \\
\text { группе* }{ }^{\circ} \mathrm{C} \pm \mathrm{SD}\end{array}$ & $\begin{array}{c}\text { Средняя t во 2 } \\
\text { группе }{ }^{*}{ }^{\circ} \mathrm{C} \pm \mathrm{SD}\end{array}$ & $\begin{array}{c}\text { Средняя t в 3 } \\
\text { группе }{ }^{*}{ }^{\circ} \mathrm{C} \pm \mathrm{SD}\end{array}$ \\
\hline нижний свод к-вы & $37.65 \pm 0.70$ & $34.52 \pm 0.34^{* *}$ & $37.5 \pm 0.48$ \\
\hline верхний свод к-вы & $36.82 \pm 0.66$ & $33.62 \pm 0.61^{* *}$ & $36.7 \pm 0.51$ \\
\hline роговица & $34.41 \pm 0.80$ & $29.42 \pm 0.74^{* *}$ & $34.6 \pm 0.66$ \\
\hline передняя камера & $35.97 \pm 0.73$ & $31.68 \pm 1.0^{* *}$ & $36.12 \pm 0.61$ \\
\hline передняя часть ст. тела & $36.96 \pm 0.77$ & $33.06 \pm 0.8^{* *}$ & $37.43 \pm 0.48$ \\
\hline средняя часть ст. тела & $37.40 \pm 0.87$ & $33.8 \pm 0.61^{* *}$ & $37.9 \pm 0.54$ \\
\hline задняя часть ст. тела & $37.50 \pm 0.88$ & $34.05 \pm 0.57^{* *}$ & $38.12 \pm 0.52$ \\
\hline сетчатка/сосудистая & $37.64 \pm 0.87$ & $34.1 \pm 0.56^{* *}$ & $38.45 \pm 0.6^{* *}$ \\
\hline с/т пространство & $37.78 \pm 0.77$ & $34.1 \pm 0.49^{* *}$ & $38.47 \pm 0.76$ \\
\hline
\end{tabular}

* $\mathrm{t}$ - температурные данные, полученные после введения кролика в наркоз.

** - p<0,05 - по сравнению со средними показателями в 1 группе. 
сетчатка/сосудистая оболочка, субтеноново пространство).

В эксперименте было подтверждено существование перепада температур между разными отделами глаза. Так в первой группе, ожидаемо, наименьшая температура была зарегистрирована на уровне наружной поверхности роговицы и после введения животных в наркоз, в среднем составила $34.41 \pm 0.80^{\circ} \mathrm{C}$, что значимо ниже по сравнению с температурой в нижнем и верхнем конъюнктивальном своде $(\mathrm{p}<0.0001)$. Температура в передней камере глаза кролика была выше по сравнению с температурой наружной поверхности роговицы и в среднем была определена на уровне $35.97 \pm 0.73^{\circ} \mathrm{C}(\mathrm{p}<0.0001)$. Максимальная внутриглазная температура зафиксирована при контакте измерительного зонда с сетчаткой и составила в среднем $37.64 \pm 0.87^{\circ} \mathrm{C}$. В субтеноновом пространстве была зарегистрирована температура $37.78 \pm 0.77^{\circ} \mathrm{C}$, которая оказалась незначимо выше температуры сетчатки $(\mathrm{p}=0.65)$. Таким образом, разность температур между наружной поверхностью роговицы и сетчаткой составила $3.23^{\circ} \mathrm{C}$, между наружной поверхностью роговицы и субтеноновым пространством $3.37^{\circ} \mathrm{C}$.

Температура различных отделов глаза, зарегистрированная в эксперименте в трех группах животных, представлена в таблице 2 .

Несмотря на изменения температуры окружающей среды в трех группах животных после введения в наркоз в различных отделах глаза общая схема распределения внутриглазной температуры сохранялась. В 1 группе температурный перепад между наружной поверхностью роговицы и передней камерой глаза составил $1.56^{\circ} \mathrm{C}$, во 2 группе $-2.26^{\circ} \mathrm{C}$, а в 3 группе $-1.52^{\circ} \mathrm{C}$. Температурный перепад между передней камерой глаза и средним отделом стекловидного тела в 1 группе составил $1.43^{\circ} \mathrm{C}$, во 2 группе $-2.12^{\circ} \mathrm{C}$, а в 3 группе $-1.78^{\circ} \mathrm{C}$. Разность температур между средним отделом стекловидного тела и сетчаткой (субтеноновым пространством) в 1 группе составил $0.24^{\circ} \mathrm{C}\left(0.38^{\circ} \mathrm{C}\right)$, во 2 группе $-0.3^{\circ} \mathrm{C}\left(0.3^{\circ} \mathrm{C}\right)$, а в 3 группе $-0.55^{\circ} \mathrm{C}\left(0.57^{\circ} \mathrm{C}\right)$. Следовательно, температурный градиент между наружной по- верхностью роговицы и сетчаткой в 1 группе составил $3.23^{\circ} \mathrm{C}$, во 2 группе $-4.68^{\circ} \mathrm{C}$, а в 3 группе $-3.85^{\circ} \mathrm{C}$.

После введения животных в наркоз во второй группе ректальная температура была самая низкая и соответствовала $37.34 \pm 0.5^{\circ} \mathrm{C}$, в первой группе $-38.73 \pm 0.94^{\circ} \mathrm{C}$, а в третьей $-39.5 \pm 0.55^{\circ} \mathrm{C}$. При этом отмечены значимые различия между ректальной температурой в 1 и 2 группе ( $=0.0002)$, между 1 и 3 группой $(p=0.0001)$, между 2 и 3 группой $(p=0.02)$.

При проведении эксперимента были зарегистрированы два случая интраоперационных осложнений в виде частичного гемофтальма во время формирования хирургического доступа и а также один случай отслоения сетчатки в послеоперационном периоде.

Обсуждение. В 1962 г. В. Schwartz и M. R. Feller опубликовали работу, посвященную измерению температуры в различных отделах глаза кроликов. Для измерения внутриглазных температур авторы применили устройство на основе термистора. В качестве измерительного зонда для регистрации внутриглазных температур использовалась металлическая игла длиной 7.62 см и диаметром 0.7 мм [4]. В 1983 г. D. R. Мау с соавторами определяли влияние перфузии передней камеры ирригационными растворами разной температуры на изменения температуры в отделах глаза у кроликов. В работе был использован термометр, изготовленный на основе термопары, представляющий собой металлический зонд с тупым наконечником диаметром 0.64 мм и длиной 2.5 см. Погрешность измерения термометра составляла $\pm 1^{\circ} \mathrm{C}$ [3]. Следует отметить, что в данных работах использовались металлические зонды, обладающие высокой теплопроводностью. Кроме того, в работе D.R. Мау с соавторами, перед измерением температуры для осуществления процессов ирригации/аспирации передней камеры выполнялось два прокола роговицы металлическими иглами диаметром 0.7 и 0.8 мм, а затем один из проколов расширялся металлическими ножницами до 3 мм. По данным экспериментальных (in vitro) и теоретических исследований, проведенных I. Fatt и J.F. Forester в 1972 г., известно, что показатели температуры тканей глаза, зарегистрированные металличе- 
скими зондами, по сравнению со значениями температуры, зафиксированными зондами с низкой теплопроводностью, могут оказаться ниже на несколько градусов [5].

В нашей работе температура, зарегистрированная у животных первой группы в передней камере глаза, составила $35.97^{\circ} \mathrm{C}$ (первая группа животных) и оказалась выше по сравнению с опубликованными ранее данными $\left(32.5^{\circ} \mathrm{C}\right.$ в работе D. R. Мау и $33^{\circ} \mathrm{C}$ в работе B. Schwartz) приблизительно на $3-3.5^{\circ} \mathrm{C}[3,4]$. Существенные различия в температурных показателях, зарегистрированных в передней камере глаза, по всей видимости, связаны с небольшим объёмом влаги передней камеры кролика, который составляет лишь 0.25-0.3 мл, а также с непосредственным контактом роговицы с окружающей средой. Поэтому введение в переднюю камеру металлического инструмента при формировании хирургического доступа и металлического измерительного зонда приводит к ощутимой потере тепла и регистрации более низких температур. В нашей работе измерительный зонд был изготовлен из политетрафторэтилена с низким показателем теплопроводности, а также формировался минимальный хирургический доступ, необходимый лишь для введения термозонда, что привело к снижению теплопотери в момент измерения температуры и регистрации более высоких показателей.

В меньшей степени теплопотери заметны при измерении температуры в стекловидном теле, поскольку его объём у кролика составляет 1-1.5 мл и отсутствует прямой контакт стекловидного тела с внешней средой. Температура в среднем отделе стекловидного тела (первая группа животных) в нашем исследовании составила $37.4^{\circ} \mathrm{C}$ и в меньшей степени отличалась от данных вышеупомянутых авторов $\left(35.5\right.$ и $\left.36.56^{\circ} \mathrm{C}\right)[3,4]$.

Таким образом, кровообращение в хориоидее является основным источником тепла в глазу животных и человека. Кровь, поступая в глаз с температурой практически равной температуре тела, формирует тепловой градиент, который индуцирует переход тепла от крови к тканям глаза. Чем интенсивнее кровообращение, тем больше количество тепла передается тканям глаза. Кровообращение в радужной оболочке и цилиарном теле также является источником тепла. Однако, в меньшей степени, поскольку кровообращение в радужной оболочке и цилиарном теле относительно мало по сравнению с кровотоком хориоидеи. Тепло, распределившееся по тканям глаза, переходит в окружающую среду через поверхность роговицы путем конвекции и радиации [9].

\section{Выводы}

1. Впервые разработан и изготовлен термоэлектрический измерительный зонд на основе термопар L-типа в корпусе стандартной канюли из материала политетрафторэтилена с низким показателем теплопроводности, что дало возможность повысить точность измерения внутриглазной температуры путем снижения теплопотерь через измерительный зонд. Также разработано многоканальное термоэлектрическое устройство с компьютерным программным обеспечением для регистрации и визуализации внутриглазной температуры, позволяющее проводить измерения в режиме реального времени с высокой точностью (в диапазоне температур $-10^{\circ} \mathrm{C} \div+120^{\circ} \mathrm{C}$ с погрешностью измерения $\pm 0.05^{\circ} \mathrm{C}$ ).

2. Используя разработанные термоэлектрические датчики, в эксперименте in vivo изучено распределение температуры в глазу кролика и подтверждено существование перепада температур между разными отделами глаза. Так, при температуре окружающей среды $23.8^{\circ} \mathrm{C}$ разность температур между наружной поверхностью роговицы и сетчаткой глаза кролика составила $3.23^{\circ} \mathrm{C}$.

3. При снижении или повышении температуры окружающей среды происходит увеличение разности температур между наружными и внутренними отделами глаза кролика. Так, при температуре воздуха $24^{\circ} \mathrm{C}$ перепад температур между наружной поверхностью роговицы и сетчаткой составил $3.23^{\circ} \mathrm{C}$, при температуре $15^{\circ} \mathrm{C}$ он составил $4.68^{\circ} \mathrm{C}$, а при температуре воздуха $31^{\circ} \mathrm{C}$ перепад температур составил $3.85^{\circ} \mathrm{C}$.

\section{Список использованной литературы}

[1]. H. Saad, M. Aladawy. Temperature management in cardiac surgery // Glob. Cardiol. Sci. Pract., 1, pp. 44-62 (2013). 
[2]. C. Purslow, J. Wolffsohn. Ocular surface temperature: a review // Eye Contact Lens, 31, pp. 117-123 (2005).

[3]. D. R. May, R. J. Freedland. Ocular hypothermia: anterior chamber perfusion // Br. J. Ophthalmol., 67, pp. 808-813 (1983).

[4]. B. Schwartz, M. R. Feller. Temperature gradients in the rabbit eye // Invest. Ophthalmol., 1(4), pp. 513-521 (1962).

[5]. I. Fatt, J. F. Forester. Errors in eye tissue temperature measurements when using a metallic probe // Exp. Eye Res., 14, pp. 270-276 (1972).

[6]. L. I. Anatychuk, N. V. Pasyechnikova, O. S. Zadorozhnyy, R. E. Nazaretyan, V. V. Myrnenko, R. R. Kobylianskyi, N. V. Gavrilyuk. Original device and approaches to the study of temperature distribution in various eye segments (experimental study) // J. Ophthalmol. (Ukraine)., 6, pp. 50-53 (2015).

UDC 617.7-537.32-073
[7]. L. I. Anatychuk, N. V. Pasyechnikova, O. S. Zadorozhnyy, R. R. Kobylianskyi, M. V. Gavrilyuk, R. E. Nazaretyan, V. V. Myrnenko. Thermoelectric device for measurement of intraocular temperature // Journal of Thermoelectricity 3, pp. 31-40 (2015).

[8]. L. I. Anatychuk, N. V. Pasyechnikova, O. S. Zadorozhnyy, R. R. Kobylianskyi, N. V. Gavrilyuk, R. E. Nazaretyan, V. V. Myrnenko, Use of Thermoelectric Device for Studying Temperature Distribution in Different Parts of the Rabbit Eye, Proceedings of research and practical conference with international engagement "The Filatov Readings 2015" dedicated to 140 anniversary of V. P. Filatov (Odessa, Ukraine), p. 188 (2015).

[9]. R. Mapstone. Determinants of ocular temperature // Br. J. Ophthalmol., 52, pp. 729-741 (1968).

Стаття надійшла до редакції 09.08.2016 р.

\title{
THERMOELECTRIC SENSORS FOR REGISTRATION OF INTRAOCULAR TEMPERATURE
}

\author{
L. I. Anatychuk ${ }^{1,2}$, N. V. Pasyechnikova ${ }^{3}$, R. R. Kobylianskyi ${ }^{1,2}$, \\ N. V. Gavrilyuk', V. A. Naumenko ${ }^{3}$, V. V. Myrnenko ${ }^{3}$, R. E. Nazaretyan ${ }^{3}$, O. S. Zadorozhnyy \\ ${ }^{1}$ The Institute of Thermoelectricity of the NAS and MES of Ukraine; \\ ${ }^{2}$ The Yuriy Fedkovych Chernivtsi National University; \\ ${ }^{3}$ State Institution "The Filatov Institute of Eye Diseases and Tissue Therapy of the National Academy of \\ Medical Sciences of Ukraine"
}

\section{Summary}

Purpose. To develop thermoelectric sensors for measuring of intraocular temperature and to study temperature distribution in different parts of the rabbit eye, depending on the ambient temperature. Materials and methods. The experiment was performed on 21 rabbits (42 eyes) which were divided into 3 groups depending on the ambient temperature. For temperature measurement, the thermoelectric device was developed consisting of the module for temperature registration, the measuring probes with thermocouple sensors and the computer with software. Results. The lowest temperature was noted in the outer corneal surface, and then it increased gradually in the inner segments of the eye and reached its maximum in the retina and subtenon space. A temperature gradient between the outer corneal surface and the retina was $3.23^{\circ} \mathrm{C}, 4.68^{\circ} \mathrm{C}$ and $3.85^{\circ} \mathrm{C}$ in Group I, II and III, respectively. Conclusions. The thermoelectric probe based on L-type thermocouples in the body of a standard polytetrafluoroethylene cannula with a low thermal conductivity was designed and manufactured. The 
temperature distribution in the rabbit eye was studied and the existence of the temperature gradient between the different parts of the eye in the in vivo experiment was confirmed. Raising and lowering of the ambient temperature increases the temperature gradient between the external and internal structures of the rabbit eye.

Keywords: thermoelectric sensor, intraocular temperature, rabbit eye

УДК 617.7-537.32-073

\title{
ТЕРМОЕЛЕКТРИЧНІ ДАТЧИКИ ДЛЯ РЕССТРАЦЇ ВНУТРІШНЬООЧНОЇ ТЕМПЕРАТУРИ
}

\author{
Л. І. Анатичук ${ }^{1,2}$, Н. В. Пасєчнікова ${ }^{3}$, Р. Р. Кобилянський ${ }^{1,2}$, М. В. Гаврилюк ${ }^{1}$, В. О. Науменко \\ В. В. Мирненко ${ }^{3}$, Р. Е. Назаретян ${ }^{3}$, О. С. Задорожний \\ ${ }^{1}$ Інститут термоелектрики НАН і МОН України; \\ 2 Чернівецький національний університет ім. Ю. Федьковича; \\ 3 ДУ «Інститут очних хвороб і тканинної терапії ім. В. П. Філатова НАМН України»
}

\section{Реферат}

Мета. Розробити термоелектричні датчики для вимірювання внутрішньоочної температури і вивчити в експерименті особливості розподілу температури в різних відділах ока кролика в залежності від температури навколишнього середовища. Матеріал та методи. Експеримент проводився на 21 кролі (42 ока). Всіх експериментальних тварин розділили на 3 групи в залежності від температури навколишнього середовища. Для вимірювання температури було розроблено термоелектричний пристрій, що складається з вимірювальних зондів з термоелектричними датчиками, мікропроцесорного модуля реєстрації температури, а також комп’ютера 3 програмним забезпеченням для візуалізації і реєстрації температурних показників в режимі реального часу. Результати. Найнижчі показники температури були зареєстровані на зовнішній поверхні рогівки та поступово зростали у внутрішніх відділах ока, досягаючи максимальних значень на рівні сітківки і в субтеноновому просторі. Температурний градієнт між зовнішньою поверхнею рогівки і сітківкою в 1 групі склав $3,23^{\circ} \mathrm{C}$, у 2 групі 4,68 ${ }^{\circ} \mathrm{C}$, а в 3 групі $3,85^{\circ} \mathrm{C}$. Висновки. Вперше розроблено та виготовлено термоелектричний вимірювальний зонд на основі термопар L-типу в корпусі стандартної канюлі з політетрафторетилену з низьким показником теплопровідності. В експерименті in vivo вивчено розподіл температури в оці кролика і підтверджено існування перепаду температур між різними відділами ока. При зниженні або підвищенні температури навколишнього середовища відбувається збільшення різниці температур між зовнішніми і внутрішніми відділами ока кролика.

Ключові слова: термоелектричний датчик, внутрішньоочна температура, око кролика 